\title{
Erratum to: Normalizing Google Scholar data for use in research evaluation
}

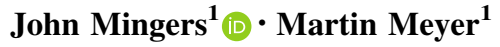

\section{Erratum to: Scientometrics}

DOI 10.1007/s11192-017-2415-x

In the original publication of this article, data in Table 6 have been published incorrectly. The correct table is provided in this erratum (Table 6).

The online version of the original article can be found under doi:10.1007/s11192-017-2415-x.

John Mingers

j.mingers@kent.ac.uk

Martin Meyer

m.meyer@kent.ac.uk

1 Kent Business School, University of Kent, Canterbury, UK 
Table 6 Actual results for conference papers

\begin{tabular}{lrrrrr}
\hline $\begin{array}{l}\text { Paper } \\
\text { code }\end{array}$ & $\begin{array}{l}\text { Citations of the } \\
\text { conference paper }\end{array}$ & $\begin{array}{l}\text { Papers found in } \\
\text { conference }\end{array}$ & $\begin{array}{l}\text { Total citations for the } \\
\text { conference papers }\end{array}$ & $\begin{array}{l}\text { Citations per } \\
\text { conference paper }\end{array}$ & CPNCS \\
\hline 123 & 0 & 0 & 0 & 0.00 & 0.00 \\
124 & 0 & 19 & 40 & 2.11 & 0.00 \\
125 & 0 & 256 & 1163 & 4.54 & 0.00 \\
126 & 0 & 195 & 1995 & 10.23 & 0.00 \\
127 & 13 & 89 & 990 & 11.12 & 1.17 \\
128 & 2 & 79 & 1600 & 20.25 & 0.10 \\
129 & 2 & 52 & 95 & 1.83 & 1.09 \\
130 & 13 & 410 & 3001 & 7.32 & 1.78 \\
131 & 3 & 157 & 130 & 0.83 & 3.62 \\
132 & 3 & 23 & 19 & 0.83 & 3.63 \\
133 & 0 & 23 & 19 & 0.83 & 0.00 \\
134 & 0 & 0 & 0 & 0.00 & 0.00 \\
135 & 5 & 129 & 240 & 1.86 & 2.69 \\
136 & 17 & 28 & 1428 & 51.00 & 0.33 \\
137 & 14 & 106 & 310 & 2.92 & 4.79 \\
\hline
\end{tabular}

